\title{
Stage I Paranasal Sinus Cancer
}

National Cancer Institute

\section{Source}

National Cancer Institute. Stage I Paranasal Sinus Cancer. NCI Thesaurus. Code C6006.

Stage I includes: T1, N0, M0. T1: Maxillary sinus: Tumor limited to the maxillary sinus mucosa with no erosion or destruction of bone. Ethmoid sinus: Tumor restricted to any one subsite, with or without bony invasion. NO: No regional lymph node metastasis. M0: No distant metastasis. (AJCC 6th and 7th eds.) 